\title{
O Que è Qualidade na Educação de Jovens e Adultos?
}

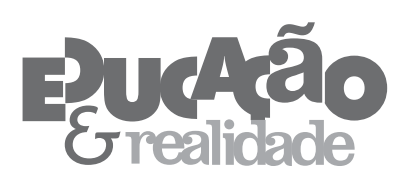

Luciana Bandeira Barcelos'

'Universidade do Estado do Rio de Janeiro (UERJ), Rio de Janeiro/RJ - Brasil

RESUMO - O Que é Qualidade na Educação de Jovens e Adultos? Este artigo tem por objetivo avaliar qualidade de ensino na modalidade educação de jovens e adultos (EJA), em um Centro de Estudos Supletivos (CES), instituição escolar da cidade do Rio de Janeiro, tomada como estudo de caso. Investigou-se o conceito de qualidade na educação, a polissemia de significados que o termo possui e os diferentes enfoques e sentidos adquiridos por esse conceito ao longo do processo histórico da educação, analisando-se o movimento de diversificação de práticas de atendimento a sujeitos jovens e adultos desenvolvidas nesse espaço, e a relação dessas práticas com a qualidade do ensino ofertado.

Palavras-chave: Educação de Jovens e Adultos. Centro de Estudos Supletivos. Qualidade na Educação de Jovens e Adultos.

ABSTRACT - What is Quality in Youth and Adult Education? This paper reports a case study focused on teaching quality as observed at a Center for Supplemental Education (CES), an educational institution located in the city of Rio de Janeiro, Brazil. The investigation attempted to identify the concept of quality in education today, the polysemy of meanings covered by the term, the various approaches reported in the relevant literature as well as the meanings it developed throughout the historical process. This was done by means of an analysis of the various practices developed in that space during the diversified movement of dealing with youth and adult subjects, and the relation between such practices and the teaching quality offered.

Keywords: Youth and Adult Education. Center for Supplemental Education. Quality in Youth and Adult Education.

Educação \& Realidade, Porto Alegre, v. 39, n. 2, p. 487-509, abr./jun. 2014.

Disponível em: <http://www.ufrgs.br/edu_realidade> 


\section{Introdução}

Direito universal de aprender, de ampliar e partilhar conhecimentos e saberes acumulados ao longo da vida, e não apenas de se escolarizar (Brasil - Documento Base Nacional Preparatório a VI Confintea, 2008, p. 13).

A citação em epígrafe destaca a importância que a educação de jovens e adultos (EJA) assume na sociedade em que vivemos, na qual a cada dia se faz presente a necessidade de se buscar novas formas de conhecer e compartilhar o conhecimento, a fim de se possibilitar o entendimento dos fenômenos e das situações vivenciadas no dia a dia, oportunizando, a cada um de nós, condições de operar nesse mundo.

Compreendida como direito fundamental da pessoa humana, por ser condição necessária à vida na sociedade atual, a educação, nessa concepção, vai além da escolarização e ocorre em diferentes espaços, pois incorpora o sentido de formação humana que, por ser humana, é ininterrupta e inacabada; por ser formação, é continuada, ou seja, se faz por toda a vida, o que pressupõe aprendizados de forma continuada, ao longo de toda a vida, entendendo que, enquanto há vida, há possibilidade de formação/transformação, pois “[...] cada ser, principalmente o ser vivo, para existir e para viver tem que se flexibilizar, se adaptar, se reestruturar, interagir, criar e coevoluir. Tem que fazer-se um ser aprendente. Caso contrário morre" (Assmann, 2007, p. 12).

Nesse processo, valorizam-se e legitimam-se saberes que jovens e adultos construíram em suas trajetórias de vida, considerando-se a diversidade dos sujeitos e a inconclusão humana, princípios básicos de qualquer ação educativa, não persistindo a ideia de idade apropriada, tampouco a existência de um único lugar de aprendizagem.

A partir do reconhecimento do direito de todos à educação - conforme expresso na Constituição Federal de 1988 (C. F. 1988) e em documentos internacionais dos quais o país é signatário - indaga-se se a concepção de EJA como formulada - um direito que implica respeitar especificidades e garantir não apenas acesso, mas permanência e sucesso, ou seja, garantir aos sujeitos condições não apenas de estar na escola, mas de aprender nessa escola, consequência e necessidade da vida contemporânea e requerimento da cidadania e que ainda se constitui como uma possibilidade de aprendizagem ao longo da vida, compreendendo todos os processos que possibilitam aos sujeitos humanizarem-se, isto é, apropriarem-se da cultura produzida pela humanidade, que não se restringe aos saberes escolares - tem se efetivado nos espaços escolares, em especial nos Centros de Estudos Supletivos (CES), que ofertam a EJA em regime semipresencial, por módulos.

Diante das dificuldades enfrentadas, face os limites impostos pelo modelo oficialmente instituído nos CES - o mecanismo leva o módulo, estuda, tira dúvidas e faz prova-, surgem embates no interior do próprio 
CES, entre professores que se inquietam com a estagnação e desgaste da escola e tentam meios de superá-la, e outros que consideram esse fato normal, devendo os alunos que a ela não se adaptarem buscar outros caminhos.

Os embates entre, o que inicialmente denomino, práticas instituídas e instituintes $^{1}$, têm como consequência tentativas de diversificação de seus modos de atendimento, ao se buscar a melhoria da qualidade do ensino ofertado.

Esse movimento, ao buscar alternativas ao modelo então instituído, pela reflexão sobre o cotidiano escolar, desenvolveu-se no CES, a que denominarei CES Bairro $\mathrm{B}^{2}$, onde realizou-se a pesquisa, a partir de 2002, impulsionado pelos embates que ocorriam em seu interior, e pelas mudanças de concepção e da base legal que sustentam a EJA, com o incentivo da Coordenação de Ensino de Jovens e Adultos (CDJA), até o final de 2009. Desse momento em diante, por força de determinações da Secretaria de Estado de Educação do Rio de Janeiro (SEEDUC/RJ), essas alternativas encontradas foram parcialmente interrompidas ${ }^{3}$.

Com o objetivo de compreender esse movimento, orientei-me para a realização de um estudo de caso. O movimento empreendido no CES Bairro B apresenta aspectos singulares, ainda que possam ser evidenciadas semelhanças com outros casos e situações. Seu estudo, embora localizado, poderá fundamentar algumas possíveis generalizações para situações análogas, e orientar novas ações, tendo em vista diversas possibilidades que a EJA ali desenvolvida oferece.

Nesse percurso, investigou-se o conceito de qualidade na educação, a polissemia de significados que o termo possui e os diferentes enfoques e sentidos adquiridos por esse conceito ao longo do processo histórico da educação, analisando-se o movimento de diversificação de práticas de atendimento a sujeitos jovens e adultos desenvolvidas nesse espaço, e a relação dessas práticas com a qualidade do ensino ofertado.

Tentar compreender como e por que se instituem nos CES tentativas de mudança de práticas instituídas, e a relação dessas práticas com a chamada qualidade de ensino, implicou buscar maior entendimento sobre concepções pedagógicas vigentes à época de sua criação, e que embasaram o modelo original e determinaram o modo de atendimento. Com o passar do tempo, apesar de superadas essas concepções no plano legal e epistemológico, ainda perduram nos espaços de oferta da EJA.

Quais foram, na prática, as mudanças efetivadas no CES em referência? Resultam de conquistas da educação de jovens e adultos ao longo dos anos, que se refletiram nas concepções legalmente estabelecidas, ou são reflexo de questionamentos surgidos nos embates do cotidiano escolar, em direção à melhoria da qualidade de ensino oferecida nesse espaço?

Para compreender tal perspectiva fez-se necessário a busca por um conceito de qualidade além do oficialmente instituído, em que se 
considerem não somente os resultados da ação educativa, mas o contexto em que ela se desenvolve, as ações dos sujeitos envolvidos e o diálogo que se estabelece no interior dos espaços escolares, buscando entender objetivos e condições de efetivação para então tentar qualificá-la.

Pensar qualidade de forma diversa do sentido que lhe é atribuído oficialmente nos impõe a necessidade de dar-lhe outro rumo, buscando outros sentidos. Esses sentidos ligam-se à práxis humana, à capacidade humana de pensar e agir. Em uma perspectiva freireana, pensar educação de qualidade implica compromisso com sujeitos que participam do ambiente escolar, que constroem e reconstroem suas vidas nesse ambiente.

Qualidade foi assumida teoricamente com sentido quantitativo - referente ao atendimento à demanda por vagas e aumento de certificação; e qualitativo - verificando como práticas de atendimento eram compreendidas e apreendidas por professores e alunos, e como recursos e dispositivos escolares se punham a serviço do atendimento. Os meandros percorridos, as questões postas à prova demonstram a necessidade de compreensão teórica, face à riqueza que a realidade apresenta, e que necessita ser apreendida.

\section{CES, Situando a Oferta no Cenário Educacional}

Os CES são unidades escolares que atendem a modalidade EJA, nos níveis fundamental e médio, por meio de ensino semipresencial, preveem avanços sequenciados de módulos, sem caráter de seriação.

Foram criados no início dos anos 1970, em plena ditadura militar, quando princípios como conscientização e participação (Soares, 1996) deixavam de fazer parte do ideário da EJA, então impregnado pelo tecnicismo educacional, caracterizado pela excessiva centralização na metodologia e na finalidade última da educação: servir ao mercado de trabalho, suprindo a escolaridade não realizada na idade considerada apropriada.

A orientação metodológica do CES, segundo Santos e Oliveira (2004, p. 9), baseou-se em módulos instrucionais e no estudo dirigido visando ao atendimento individualizado por meio da autoinstrução, com o auxílio do que ficou conhecido como orientador de aprendizagem, que atendia estudantes em horários predeterminados.

Não havendo frequência obrigatória, as idas do aluno ficavam a critério dos processos de ensino e aprendizagem em curso. Segundo Santos e Oliveira (2004, p. 9), esses processos reduziam-se à "[...] aprendizagem das instruções contidas nos módulos instrucionais", acentuando-se a certificação rápida, em detrimento do conhecimento, supostamente por pressão social e por necessidade implícita de o aluno "recuperar o tempo perdido".

Os CES foram considerados a solução mais viável para sujeitos jovens e adultos, de modo a atender, ao mesmo tempo, "[...] ao trinô- 
mio: tempo (rapidez de instalação), custo (aproveitamento de espaços ociosos) e efetividade (emprego de metodologias adequadas)" (Santos; Oliveira, 2004, p. 7).

Criava-se um modelo contraditório ao oportunizar um espaço de atendimento individual que permitia, ao professor, olhar particularmente o aluno, observando deficiências e necessidades, ao mesmo tempo em que se exigia que esse mesmo professor o inserisse em um padrão previamente determinado, nem sempre adequado, que desconsiderava a trajetória anterior de cada um, sujeitos em maioria oriundos de formação escolar - parafraseando Souza (2000, p. 3) - “[...] marcada por problemas de seletividade, descontinuidade e fraturas [...]”, o que gerou uma série de inquietações no espaço escolar, entre professores e alunos.

Tais inquietações, aliadas às modificações legais, levam a tentativas de superação do modelo tradicional do CES, o mecanismo leva o módulo, estuda, tira dúvidas e faz prova, instituindo-se práticas diversificadas de atendimento, na busca pela melhoria da qualidade do ensino ofertado nesse espaço, e a questionamentos sobre o que seria qualidade de ensino na educação de jovens e adultos.

\section{CES Bairro B, Caminhos e Descaminhos entre Instituinte e Instituído}

O CES Bairro B é uma unidade escolar da SEEDUC/RJ e iniciou seu funcionamento no ano de 1991, nas dependências de uma unidade do Serviço Nacional da Indústria (SENAI), situado em um bairro da zona Oeste da cidade. Em 1995, com o encerramento do contrato de comodato firmado entre a Secretaria de Educação e o SENAI, o CES Bairro B foi transferido para as dependências de um CIEP localizado nas proximidades, onde permanece até hoje, ocupando quatro salas de aula.

Durante o período em que funcionou nas dependências do SENAI, de 1991 a 1995, dispunha de toda infraestrutura, ainda que os espaços não fossem de uso exclusivo do CES. Apesar de se dispor de todos esses recursos, estes não eram utilizados em subsídio à diversificação do atendimento. Apenas cursos de suprimento de redação e de inglês eram oferecidos, ficando subentendido que o único modo de funcionamento da escola era a orientação individual e a realização de avaliações.

Tal forma de atendimento foi mantida no CES Bairro B desde sua criação, em 1991, até o ano de 2002, observando-se os objetivos e modos de funcionamento originalmente estabelecidos, oferecendo atendimento conforme previsto no modelo original, o mecanismo "leva o módulo, estuda, tira dúvidas e faz prova”.

Somente em 2002, com o incentivo da CDJA, as polêmicas que ocorriam em função das modificações legais referentes à EJA, vigentes à época (especialmente após o Parecer CNE/CEB n. 11/2000) começam a ganhar consequência, tendo o movimento de diversificação de práti-

Educação \& Realidade, Porto Alegre, v. 39, n. 2, p. 487-509, abr./jun. 2014.

Disponível em: <http://www.ufrgs.br/edu_realidade> 
cas de atendimento seu marco inicial na proposição da CDJA, em 2002, de estender aos CES a realização da Semana EJA, comumente realizada nas escolas que ofertavam a modalidade. A recomendação expressa era de que se realizassem atividades diversificadas, de forma coletiva, oficinas, palestras etc.

Tal determinação provocou intensos debates entre professores que, imbuídos de um espírito de praticidade, alegavam não haver espaço disponível para que quaisquer atividades fossem realizadas. Além dessas argumentações, também se suspeitava que os alunos não iriam à escola participar de atividades pela falta de tempo, razão, em muitos casos, da escolha do CES para a conclusão de estudos, por fugir do modelo de aulas diárias.

Poucos tinham consciência de ser esse um movimento que expressava outras convicções podendo possibilitar, ao longo do tempo, mudanças mais profundas de concepções e não apenas de oferta de atividades diversificadas.

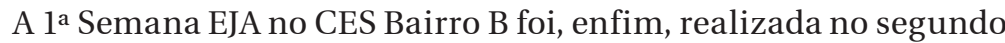
semestre de 2002. Organizada de forma precária, devido à falta de espaço e material, aconteceu com oferta de oficinas de artes, exibição de filmes, palestras, aulas práticas, seminários, apresentação de grupo de teatro formado por alunos do CES.

O espaço surgiu com a necessidade. O CES ficou lotado, algumas atividades foram repetidas devido à procura de alunos. Era a primeira vez, em 11 anos, que se via um movimento como este no CES Bairro B. Grata surpresa para todos, marcando o início da oferta de outras atividades, para além do empréstimo de módulos e da realização de avaliações. O primeiro desafio vencido que levou a meditar sobre as contribuições que tais atividades podem trazer ao cotidiano da escola.

Nos anos seguintes, a Semana EJA cresceu de tal maneira que foi necessário à escola providenciar espaço externo para realizar o evento. Ao mesmo tempo, germinava em seu interior a ideia de se incorporarem as atividades da Semana EJA de forma permanente aos modos de atendimento do CES.

Surgiram ideias, discutiram-se proposições e, aos poucos, foi tomando força na escola a possibilidade de atender grupos de alunos, permanentemente, no CES, além da possibilidade de se oferecerem outras estratégias de conclusão de curso, tendo em vista que uma das solicitações mais prementes no CES diz respeito à urgência na terminalidade.

Muitos alunos são sujeitos privados da escolarização formal, que desenvolveram potencialidades e encontraram formas de sobreviver na sociedade grafocêntrica e necessitam, por vezes, do reconhecimento formal de suas habilidades.

Reconhecer que a aprendizagem também se dá em diferentes espaços é um desafio presente nos espaços de escolarização formal. No CES não é diferente, e buscar esse reconhecimento para além das alega- 
ções de que o interesse dos alunos é apenas pela certificação imediata, feita em curto prazo, representa um desafio ainda maior, pois é tênue a linha que separa o aligeiramento da formação - discurso recorrente no CES, e o reconhecimento de saberes válidos, como forma de organizar a metodologia de ensino e a oferta de outros modos de conclusão.

Para atender essa imperiosa necessidade foram criados dois projetos, ambos tendo por objetivo a aceleração de estudos. O primeiro, denominado Acelera CES, vinculava-se aos módulos e, o segundo, denominado inicialmente apenas como provão, a exemplo dos Exames Supletivos, e posteriormente nomeado exame descentralizado, era fruto da essencialização de conteúdos e da utilização de questões do dia a dia.

Para alguns, apenas meio de auxiliar e otimizar a conclusão do curso; para outros, o reconhecimento da existência de diversos saberes válidos e de diversas formas de aprender. O CES abria ainda mais seu modelo não seriado, permitindo a oferta da EJA com diferentes proposições, possibilitando à diversidade de sujeitos e interesses um atendimento também diversificado.

Diversificar práticas de atendimento não significa apenas agrupar alunos, mas sim promover situações em que possa emergir o reconhecimento de potencialidades, de saberes, e de relações desses saberes com a vida, superando a compartimentalização e a instrumentalização dos módulos. Implica, também, mudança de atitude, para compreender a educação como um processo de vivência e compartilhamento de experiências entre pessoas diferentes que, portanto, produzirá resultados diferentes.

Percebo ser muito tênue a linha que separa o instituinte do instituído. Linhares (2007, p. 149), discorrendo sobre experiências instituintes, afirma que elas “[...] não são puras, não se protegem em redomas e, por isso mesmo, se misturam sem parar com as dimensões já instituídas”, ao mesmo tempo em que o instituído "[...] também procura apropriar-se delas e, assim garantir alguma dose de vitalidade” (Linhares, 2007, p. 157).

O instituinte está intrinsecamente ligado ao instituído na escola, por vezes sendo utilizado para confrontá-lo, legitimando-se pelo confronto, gerando situações conflituosas no ambiente escolar, entre defensores e opositores à sua implementação. As experiências instituintes estão: "Sempre em confronto com o já instituído, do qual não pode ser separado. Pelo contrário. Umas e outras estão sempre em litígios, em afirmações que não são praticadas no vazio, mas que buscam expandir-se, ou seja, penetrar nos espaços e nos tempos que lhe são antagônicos" (Linhares, 2007, p. 157).

Práticas oriundas de experiências instituintes constituem, assim, ato político, que reafirma os diferentes sentidos e significados atribuídos à educação. Nas palavras de Freire (1997, p. 119-120), “Não há edu-

Educação \& Realidade, Porto Alegre, v. 39, n. 2, p. 487-509, abr./jun. 2014. 493

Disponível em: <http://www.ufrgs.br/edu_realidade> 
cação sem objetivos, sem finalidades. É isto que a fazendo diretiva, não permite sua neutralidade ou a neutralidade do educador". No contexto em que se inserem, de uma escola altamente padronizada, como o CES, essas práticas adquirem força e valor inestimáveis. Mesmo quando não representam rompimento total e mudança de concepção, ainda assim constituem brechas por meio das quais se busca instituir um novo modo de pensar a educação de jovens e adultos, nesse espaço.

De posse dessa compreensão, cabe indagar se o CES Bairro B, ao ampliar seus modos de atendimento tem conseguido superar sua proposição inicial de adequação dos sujeitos a um único modelo, para reconhecer e legitimar outros saberes e se essa nova proposição tem contribuído para a melhoria da qualidade do ensino que oferta.

\section{A Busca por um Conceito de Qualidade na EJA}

É possível dizer que um dos maiores desafios da educação brasileira na atualidade é promover a melhoria da qualidade de ensino oferecido nas escolas públicas, ou seja, promover a garantia do direito, por mim entendida como garantia de acesso, permanência e sucesso. Parafraseando Oliveira e Araújo (2005), a efetivação de uma escola que consubstancie, de fato, um projeto de emancipação e inserção social, que tenha como pressuposto um ensino básico de qualidade para todos e que não (re)produza mecanismos de diferenciação e de exclusão social.

Após um período inicial de expansão do sistema educacional, com a ampliação do acesso e a quase universalização do ensino fundamental, estamos diante de novos desafios: continuar garantindo acesso; estender a obrigatoriedade às demais séries da educação básica e modalidades; possibilitar condições de permanência e de sucesso escolar - situações diretamente ligadas à qualidade de ensino oferecido pelos sistemas públicos. Além disso, temos outro desafio, a promoção do regime de colaboração entre os entes federados, missão árdua, haja vista a imensa desigualdade que caracteriza o país.

Embora a C. F. 1988 estabeleça no parágrafo VII, do artigo 206 (s. p., consulta online), "a garantia de qualidade" de ensino, e a LDBEN n. 9394/96 também o faça no artigo 30, inciso IX, ao declarar que “[...] o ensino será ministrado com base nos seguintes princípios [...] garantia de padrão de qualidade” e no art. 4, inciso IX assegurar “[...] padrões mínimos de qualidade de ensino, definidos como a variedade e quantidades mínimas, por aluno, de insumos indispensáveis ao desenvolvimento do processo de ensino-aprendizagem”, não existem parâmetros nas leis que definam a qualidade em relação à educação brasileira.

A C. F. 1988 garante ainda, no artigo 208, inciso VII (s. p., consulta online), que esse atendimento deve ser efetivado “[...] em todas as etapas da educação básica, por meio de programas suplementares de material didático escolar, transporte, alimentação e assistência à saúde” e a LDBEN ratifica tal preceito nos mesmos termos, no art. 4, inciso VIII. 
Mas, embora defina que a educação pública dever ser de qualidade, a legislação brasileira não estabelece de forma precisa em que consiste essa qualidade. Segundo Oliveira e Araújo (2005, p. 17):

\begin{abstract}
[...] se a legislação brasileira incorporou o conceito de qualidade do ensino a partir da Constituição Federal de 1988, essa incorporação não foi suficiente para estabelecer de forma razoavelmente precisa em que consistiria ou quais elementos integrariam o padrão de qualidade do ensino brasileiro, o que dificulta bastante o acionamento da justiça e, caso de oferta de ensino com má qualidade. Afinal, como caracterizar um ensino com ou sem qualidade, se não há parâmetros para o julgamento?
\end{abstract}

Essa inconclusão legal ${ }^{4}$, aliada a polissemia de sentidos que caracteriza o termo qualidade, torna necessária maior compreensão do significado atribuído pelos diferentes sujeitos ao termo qualidade na educação e suas implicações nos processos escolares, considerando-se que qualidade é um conceito cujo valor é socialmente construído e está intrinsecamente ligado a uma concepção de sociedade e, consequentemente, de educação.

Por vivermos em um mundo altamente heterogêneo, com diversos interesses em disputa e, consequentemente, diversos modos de pensar, muitas serão as definições possíveis de serem atribuídas ao termo qualidade, possibilitando a transformação do discurso da qualidade em um discurso híbrido, onde posições divergentes convivem mesmo em momentos de atualização de conceitos.

Segundo Demo “[...] qualidade aponta para a dimensão da intensidade, tem a ver com profundidade, perfeição, principalmente com participação e criação. Está mais para o ser do que para o ter" (2009, p. 11). Qualidade liga-se à ação humana, sempre incontrolável e inconstante, capaz de se sobrepor ao anteriormente fixado, de agir contra os efeitos de um poder totalizante e englobante. Qualidade implica participação e compromisso, oportunidade de desenvolver potencialidades e a capacidade de ser sujeito de sua própria ação.

Nesse sentido, oferecer uma educação de qualidade a sujeitos jovens e adultos, implica conhecer sua realidade e reconhecer necessidades, possibilidades e aspirações, incluindo-os nesse processo. E nos impõe a necessidade de pensar a educação de jovens e adultos não para os sujeitos jovens e adultos, mas, sim, com os sujeitos jovens e adultos, situação que Freire apontava ainda na década de 1960.

Ao vincular educação e qualidade de ensino, termos abrangentes e complexos, é preciso considerar que sua definição dependerá do contexto político em que se estabelecerem as finalidades da ação educativa. Logo, verificar se os resultados obtidos pelos alunos do CES denotam qualidade nos processos oferecidos, decorrentes de práticas pedagógicas instituintes, ou seja, tentar identificar se as práticas instituintes desenvolvidas no CES evidenciam avanços em direção à efetivação do

Educação \& Realidade, Porto Alegre, v. 39, n. 2, p. 487-509, abr./jun. 2014. Disponível em: <http://www.ufrgs.br/edu_realidade> 
direito e as relações que essas práticas têm com a chamada qualidade de ensino, implica tentar compreender o termo qualidade ao longo da história da educação brasileira, tanto do ponto de vista histórico, quanto político, a fim de poder analisar os dados obtidos e situações observadas no percurso da pesquisa, de forma contextualizada, entendendo que todo conceito polissêmico parte de uma concepção de mundo, de sociedade, de educação.

Qualidade é um dos conceitos mais disputados da atualidade, sendo a palavra de ordem no discurso da escola, utilizada para legitimar o que a sociedade espera de sua atividade. No dizer de Assmann:

No futuro ninguém sobreviverá, em meio à competitividade crescente do mercado, sem aquela educação fundamental que lhe entregue os instrumentos para uma capacitação de alfabetizado flexível, apto para adaptar-se a mercados de trabalho cada vez mais flexíveis. No fundo, é a isso que se refere à questão da qualidade. E é também para isso que convergem os interesses do empresariado numa universalização da educação básica (1998, p. 186).

Ou seja, sob o discurso da qualidade subsistem as intenções da sociedade atual acerca da ação educativa. Se nossa opção é buscar uma sociedade mais justa e mais humana, precisamos pensar essa qualidade para além do proposto, a simples análise tempo/custo/efetividade, que parafraseando Oliveira (2007, p. 33), considera como indicador de qualidade na educação "[...] apenas resultados de produto, difundindo a ideia de que os processos educacionais não são importantes”, o que implica analisar o contexto em que se desenvolve a ação educativa, buscando entender seus objetivos e condições de efetivação, para então tentar qualificá-la, tendo por base uma configuração que considere, além das condições de efetivação, a atuação dos sujeitos e os processos envolvidos na construção de uma escola dita de qualidade.

Pensar a questão da qualidade de forma diversa nos impõe a necessidade de dar-lhe um rumo diferente do atual, tentando retomar um território já ocupado e "libertá-la para outros sentidos" (Assmann, 1998, p. 187), ligados à práxis humana, à capacidade humana de pensar e agir. Nesses "outros sentidos", os indicadores de resultados representariam apenas uma das dimensões do conceito, e não sua totalidade. Conforme Oliveira (2007), o conceito de qualidade poderia ser definido a partir de três dimensões: resultados, insumos e processos.

A dimensão resultados estaria ligada à questão do fluxo escolar e aproveitamento do ensino, a dimensão insumos, às condições em que se efetivam os processos escolares, abrangendo questões financeiras, de infraestrutura, sociais, etc., reconhecendo a diversidade que caracteriza os espaços escolares, e a dimensão processos, “[...] a procedimentos analíticos que sejam capazes de valorar os processos no interior da escola" (Oliveira, 2007, p. 34), sejam eles de ensino e aprendizagem, gerenciais e relacionados ao clima escolar, identificados como capazes 
de influenciar positivamente a efetivação de uma escola de qualidade, na contramão do que preconizam as propostas do mercado, que focam apenas nos resultados, desconsiderando os demais fatores que influenciam a qualidade escolar.

Ou seja, pensar uma educação de qualidade está muito além de condicioná-la aos ditames do mercado econômico, que veem apenas os resultados desse processo. Pensar uma educação de qualidade implica compromisso com os sujeitos que habitam o ambiente escolar, que constroem e reconstroem suas vidas nesse ambiente. No dizer de Freire (apud Coimbra; Oliveira, 2011, p. 83), “[...] um compromisso social assumido em busca de uma sociedade menos excludente e mais humanizada”.

Segundo Oliveira e Araújo, podemos dizer que, ao longo da história da educação brasileira,

\begin{abstract}
Três significados distintos de qualidade foram construídos e circulam simbólica e concretamente na sociedade: um primeiro, condicionado pela oferta limitada de oportunidades de escolarização, um segundo, relacionado à ideia de fluxo, definido como número de alunos que progridem ou não dentro de determinado sistema; e, finalmente, a ideia de qualidade associada à aferição de desempenho mediante testes em larga escala $(2005$, p. 8$)$.
\end{abstract}

O primeiro significado origina-se na oferta limitada. Por conta desse fato, compreendia-se qualidade como possibilidade ou impossibilidade de acesso a uma escola criada na perspectiva da classe privilegiada, que permitia o acesso de poucos, oriundos de famílias letradas, convivendo em ambientes parecidos com o que seria exigido na escola.

No dizer de Paro "[...] a escola não precisava ser boa, ela podia dar-se ao luxo de ser ruim, porque ela não era para as massas [...] quem ia para a escola, aprendia apesar da escola" (2010, p. 84). Tal visão perpetua-se ainda hoje nos espaços escolares, onde não é difícil encontrar tais discursos, que evocam o retorno à escola do passado, como se ela fosse referência de qualidade.

Essa concepção de escola de qualidade, vinculada ao acesso, fez as propostas de enfrentamento à demanda por escolaridade reduzirem-se à construção de prédios, sem a preocupação com o que se faria nesses espaços, o que gerou obstáculos em relação ao prosseguimento dos estudos da população que, com a expansão e democratização das redes, por força de reivindicações populares, pôde finalmente ocupar seu espaço na escola, produzindo um segundo significado para o termo qualidade na educação, agora ligado ao fluxo escolar.

Com a entrada de uma parcela maior da população na escola, torna-se evidente sua falta de estrutura para atender a essa nova população. No momento em que amplia-se o acesso, e todas as camadas populares passam a ocupar de maneira ostensiva os espaços antes restri-

Educação \& Realidade, Porto Alegre, v. 39, n. 2, p. 487-509, abr./jun. 2014. 497 Disponível em: <http://www.ufrgs.br/edu_realidade> 
tos a uma pequena minoria, evidencia-se a baixa qualidade do ensino, pensado para atender a poucos.

Segundo Beisiegel, “[...] foi a incorporação quase completa de todos à etapa obrigatória de escolarização que fez emergir o problema da qualidade em uma configuração inteiramente nova" (1981, apud Oliveira; Araújo, 2005, p. 7).

Ainda, de acordo com Beisiegel, “[...] a escola, hoje, em todos os níveis abriga contingentes extraídos das mais diversas camadas da sociedade e passa a reproduzir, na esfera limitada da educação escolar, todas as dificuldades inerentes à preparação de uma imensa e heterogênea coletividade" (2005, p. 107). O público da escola muda, mas sua forma de organização e funcionamento não.

No dizer de Oliveira e Araújo (2005, p. 10), “[...] os obstáculos à democratização do ensino foram transferidos do acesso para a permanência com sucesso dentro do sistema escolar" e tem início um "novo tipo de seletividade", com a construção de um novo conceito de qualidade, agora vinculado à ideia de fluxo escolar, ou seja, ao número de alunos que conseguem progredir dentro de determinado sistema de ensino. Por esse conceito, seria de qualidade a escola que tivesse uma saída de alunos comparável à entrada.

Considerando-se que a escola não foi pensada, tampouco estruturada, para atender a grande maioria da população, logo surgem problemas referentes ao fluxo escolar que começam a ser enfrentados na perspectiva da inadequação dos sujeitos, com sua responsabilização pelo fracasso, característica da sociedade capitalista, individualista, que vê a educação como ação individualizante, de desvelamento de verdades universais, de propagação de valores e verdades legitimados pela sociedade.

Tal perspectiva gera um processo de "expulsão dos alunos", entendido pela escola como evasão, responsabilizando-se mais uma vez o sujeito pelo não aproveitamento da oportunidade que lhe foi dada. Torna-se evidente que não basta ampliar o acesso à educação, mas garantir ao indivíduo condições para permanência e sucesso, com qualidade, no ambiente escolar. Dar mais a quem tem menos e não na mesma proporção a todos, retrata a concepção de equidade que tem sido defendida como função da EJA, e, portanto, básica para qualquer política educacional a ser implementada.

Surgem, então, os programas de correção de fluxo, com a adoção da promoção continuada e de aceleração de aprendizagem, que, se pensados sob outra ótica, poderiam possibilitar a melhoria da aprendizagem - ao promoverem um novo olhar sobre o aluno e o repensar das práticas escolares, mesmo que de forma direcionada - mas que, em sua maioria, reduzem-se à tentativa de melhoria do fluxo escolar, garantindo a qualidade de uma escola que consegue "formar" mais pessoas, não importando a condição em que se dá essa pretensa formação. Tarefa 
que se revela infrutífera, pois conforme destacam Oliveira e Araújo, “[...] ficou mais fácil entrar no ensino fundamental, mas continua muito difícil concluí-lo" (2005, p. 11).

Ainda segundo Oliveira e Araújo, ao referir-se às políticas e programas de correção de fluxo:

\begin{abstract}
Pode-se discutir se essas políticas e programas surtem o efeito de melhoria da qualidade de ensino. Na verdade, o seu grande impacto observa-se nos índices utilizados até então para medir a eficiência dos sistemas de ensino, não incidindo diretamente sobre o problema (2005, p. 10).
\end{abstract}

Evidencia-se a necessidade de se pensar em novos meios de se qualificar a escola, pois se as políticas e programas de melhoria do fluxo então vigentes incidem sobre os índices de produtividade, eles deixam de ser válidos para aferir a qualidade, pois como verificar a qualidade de uma escola que, de certa maneira, induz a aprovação dos alunos?

Assim, a educação brasileira incorpora o terceiro significado do termo qualidade na educação, a ideia de qualidade associada à "[...] aferição de desempenho mediante testes em larga escala”, que consiste em aplicar, ao longo e ao final dos cursos, testes que procuram avaliar a aprendizagem obtida. No dizer de Oliveira e Araújo "[...] a qualidade indicada pela capacidade cognitiva dos estudantes” (2005, p. 12), como medida, um conceito importado para nosso sistema educacional.

Tal modelo leva ao ranqueamento das escolas, conforme o resultado obtido nas avaliações a que são submetidos seus alunos, ao longo e ao final do curso, estabelecendo-se índices de aproveitamento a serem progressivamente superados, instituindo-se premiações aos professores, funcionários e, em alguns casos, alunos, por meio de programas de incentivo ao cumprimento de metas estabelecidas conforme diagnóstico realizado pelo sistema. Nesse modelo, ensinar resume-se a preparar os alunos para a realização da avaliação externa, perdendo-se o sentido de formação humana.

No caso do CES, tal modelo ainda não se instituiu por completo, porque os critérios em que se baseiam as metas estabelecidas pela SEEDUC/RJ para as unidades escolares da rede estadual não contemplam as especificidades do CES, tendo gerado uma série de controvérsias entre os professores, que se sentem excluídos do processo avaliativo da rede, que gera benefícios financeiros, além de promover a competição entre escolas, numa lógica característica da meritocracia, tratando-se a educação não como processo de compartilhamento de experiências, mas como uma competição.

Especificamente no CES, é preciso redobrar esse cuidado, pois a ideia de tempo/custo/efetividade, que constitui o trinômio sob o qual se assenta a origem da escola, ainda se faz presente nos dias atuais, no discurso oficial do sistema e no ideário de professores e alunos.

Educação \& Realidade, Porto Alegre, v. 39, n. 2, p. 487-509, abr./jun. 2014.

Disponível em: <http://www.ufrgs.br/edu_realidade> 
Permanecem no CES as tentativas de condicionar o atendimento dos professores à efetivação do trinômio tempo/custo/efetividade que, apesar de nunca alcançado, ainda é utilizado como referencial de atendimento, estando o quantitativo de professores, e até mesmo de funcionários e recursos recebidos pela escola a ele ligados, estabelecendo-se médias de atendimento em função do tempo trabalhado por docente, como se atender mais pessoas em tempo menor atestasse a eficiência da prática docente e fosse sinônimo de atender com qualidade.

Retomando minha perspectiva inicial, em busca de um sentido diferenciado para o conceito de qualidade, à luz do qual busquei compreender as práticas do CES Bairro B, optei por definir qualidade de ensino por meio de aspectos quantitativos - acesso a matrículas, a condições mínimas de permanência e à terminalidade de processos de escolarização -; mas, também, por meio de aspectos qualitativos - que ponham em cheque processos educacionais, resultados deles advindos e efeitos na vida cotidiana dos alunos.

Traduzo, assim, um dos elementos de qualidade em um CES que oferta EJA: expressão do respeito ao direito à educação para todos. Não se pode pensar primeiro em ampliação da oferta e, posteriormente, em qualidade do processo, pois conforme destaca Paiva (2006, p. 15), “[...] a educação de jovens e adultos, como direito não dado, mas arrancado do chão, não pode mais escapar das mãos dos que por ele têm despendido a vida”.

\section{Indicadores de Qualidade no CES}

Ao buscar compreender qualidade de ensino em um CES, tomei como fonte de dados as dimensões processos e resultados, representadas pelos indicadores processos de ensino e aprendizagem; modo como concluem o curso (se por meio do que chamamos de práticas instituídas ou instituintes), verificando como são implementados os processos escolares definidos no projeto político pedagógico da escola.

$\mathrm{O}$ indicador processos de ensino e aprendizagem refere-se ao modo como se ensina e se aprende em uma unidade CES. Nas palavras de Assmann (1998, p. 7), “[...] como se dá a experiência do conhecimento na vida das pessoas", considerando-se a diversidade que caracteriza a espécie e a relação intrínseca entre conhecimento e vida, “[...] o que faz com que um ensino mereça o nome de processo pedagógico [...] esse encantamento - por criar e ver emergir a celebração da alegria de conhecer na vida dos aprendentes".

Nesse sentido, os modos de atendimento empregados por alunos e professores para efetivar a conclusão do curso foram observados considerando-se esse viés, identificando nas práticas em desenvolvimento na escola a concepção por mim assumida: se por meio de práticas instituídas ou instituintes, estas referidas a formas diferentes do modelo original de promover o processo pedagógico. Por fim, se ainda ocorre a 
ressignificação de práticas instituídas, por caminhos mais autônomos e independentes.

A educação do momento presente está exigindo, certamente, mais do que tem sido oferecido pelos modelos escolares, diante da aceleração dos processos de produção de conhecimento. $\mathrm{O}$ aumento da expectativa de vida, o desenvolvimento tecnológico em curso aliados à valorização de bens materiais, que têm levado ao consumismo desenfreado e à perda de valores humanos, são elementos que demonstram mudanças em ebulição na sociedade contemporânea. Segundo Portal et al. (2009, p. 942), “[...] vive-se em pleno século XXI com a dicotomia entre a convicção na esperança de um mundo mais humano e a cega valorização dos bens materiais e os valores que embasam as lógicas produtivas".

Nesse contexto em permanente mudança, estabelecer um conceito de qualidade torna-se muito difícil, diante das demandas e expectativas que a escola precisa atender. Quando discutimos qualidade em uma escola para todos - o que implica respeitar diferenças -, há que se pensar o paradoxo instituído quando se declara a necessidade de propiciar a todos os diferentes o direito à educação e, ao mesmo tempo, aceitar que se avalie de maneira uniforme as escolas, tal como vem sendo realizado. Nas palavras de Freire (apud Gadotti, 2010, p. 7), “[...] precisamos construir uma nova qualidade", que consiga acolher a todos e a todas.

Essa nova qualidade implica ir além da avaliação de resultados, para considerar condições iniciais de cada sujeito, insumos recebidos e processos que a escola desenvolve na tentativa de atender a cada um conforme sua necessidade, o que por si só representa imenso desafio. Grande parte das escolas não vem conseguindo enfrentá-lo pela lógica que impera nos espaços escolares: a de homogeneização de percursos, como forma de promover o sucesso escolar. Ainda nas palavras de Freire (apud Gadotti, 2010, p. 9), “[...] não basta matricular os pobres na escola. É preciso matricular com eles também a sua cultura, os seus desejos, seus sonhos, a vontade de ser mais".

Essa vontade de ser mais é que anima e impulsiona os sujeitos jovens e adultos a buscar novamente os espaços escolares, confirmando a afirmação de Freire (1997, p. 55), de que “[...] o inacabamento do ser ou sua inconclusão é próprio da experiência vital. Onde há vida, há inacabamento".

Essa característica, a incompletude, define o ser humano e sua necessidade de saber, de aprender continuamente, por toda a vida. A consciência do inacabamento faz homens e mulheres terem esperança de que esse aprender, que se estende pela vida, possa ajudar a transformá-la. A consciência da incompletude produz esperança e reafirma o sentido e a importância do educar.

O direito de cada um à educação é, assim, entendido como mais uma possibilidade de aprendizado no mundo. Portanto, processos que valorizem o sujeito no exercício de sua ação, mesmo que influenciados por condições infraestruturais e de insumos recebidos, imbricam-se

Educação \& Realidade, Porto Alegre, v. 39, n. 2, p. 487-509, abr./jun. 2014. Disponível em: <http://www.ufrgs.br/edu_realidade> 
com a qualidade dos profissionais da escola que, por sua vez, integram processos mais complexos que definem qualidade da educação. Reiterando Demo (2009, p. 11), “[...] qualidade aponta para a dimensão da intensidade, tem a ver com profundidade, [...] principalmente com participação e criação". Qualidade liga-se à ação humana, sempre incontrolável e inconstante.

Qualidade da educação está, assim, intrinsecamente ligada à práxis humana, à condição de "[...] sujeitos criativos, imaginativos, produtores de sentidos, significados e símbolos, capazes de fazer perguntas que vão além do estritamente físico, racional ou sentimental" (Moraes, 2009, p. 14-15), seres em permanente construção, o que coincide com o pensamento freireano.

Em se tratando do CES, pensar qualidade de ensino implica considerá-la processo de muitas dimensões, na acepção polissêmica do termo, cuja busca pressupõe permanente adaptação de seus modos de atendimento, alterando práticas cotidianas, de forma a melhor responder a especificidades de seu público.

\section{Diálogos com Dados do CES Bairro B}

O número de alunos matriculados frequentando o CES Bairro B, em 2009, perfazia um total de 2084, conforme dados do Educacenso/2009. Esse número, se comparado ao total de concluintes dos dois níveis de ensino no mesmo ano - 425 alunos, sendo 87 de ensino fundamental (EF) e 338 de ensino médio (EM) - aponta para dificuldades de conclusão do curso nesse modo de ensino, com apenas $20 \%$ de concluintes.

Entretanto, considerado o total de matrículas e concluintes até 2009, verifica-se aumento da certificação no período estudado (2002 a 2009), o que talvez possa ser explicado, entre outros fatores, pelas tentativas de diversificação dos modos de atendimento. Observe-se: de 1991 a 2001 (período de 11 anos de atividades no modelo emprestar módulos, tirar dúvidas e fazer provas) foram certificados 1183 alunos, tendo sido efetuadas 12.642 matrículas; de 2002 a 2009 (em oito anos) certificaram-se 6357 alunos, tendo sido efetuadas 24.968 novas matrículas.

Comparativamente ao número de matrículas efetuadas, o número de alunos que conseguem concluir o curso nesse modo de ensino ainda é pequeno, o que representa um contraponto ao trinômio inicial sob o qual se assenta a estrutura da escola, a ideia de tempo/custo/efetividade.

Apesar das variáveis envolvidas no aumento do número de concluintes (sujeitos certificados), a diversificação de modos de atendimento também contribuiu, constatada quando se identificaram modos de conclusão na amostra. Esses números, por si só, não significam melhoria da qualidade da oferta, embora apresentem evidências de melhoria de fluxo de entrada e saída de alunos, em um período determinado. 


\section{Modo de Conclusão do Curso: reflexões}

$\mathrm{Na}$ análise dos dados amostrais referentes aos modos de conclusão, chamam atenção as diferentes estratégias utilizadas pelos alunos para a conclusão do curso, principalmente pelo fato de a minoria concluir apenas no sistema modular.

\section{Concluintes 2009 - conforme estratégia utilizada}

\begin{tabular}{|l|c|}
\hline \multicolumn{1}{|c|}{ Modo de Conclusão do Curso } & N $^{\circ}$ Concluintes \\
\hline Módulo a módulo & 08 \\
\hline Módulos e outras atividades/estratégias & 216 \\
\hline Apenas outras atividades/estratégias & 201 \\
\hline Total & 425 \\
\hline
\end{tabular}

Fonte: desenvolvida pela autora.

Do total de 425 concluintes de EF e EM, apenas $2 \%$ concluem todas as disciplinas módulo a módulo, evidenciando a dificuldade de estudar no modelo originalmente proposto, cuja formulação se assenta na ideia de formar o maior número de pessoas, no menor tempo e com o menor custo possível. Os dados parecem contestar essa ideia, já que a maioria demonstra necessitar de outros mecanismos para efetivar a conclusão. O baixo número de certificações nos anos anteriores à diversificação de formas de atendimento já o demonstrara, parecendo confirmá-la a análise dos modos utilizados pelos alunos para a conclusão do curso.

Desmembrando os dados, obtêm-se em cada nível de ensino o seguinte: no EF, $4 \%$ do total de 87 alunos da amostra concluiu todas as disciplinas por módulo; $52 \%$ concluiu utilizando módulos e outras atividades/estratégias; e $44 \%$ apenas outras atividades/ estratégias.

No EM, dos 338 alunos da amostra, temos $1 \%$ que concluiu apenas por módulos, $51 \%$ por módulos e outras atividades/estratégias e $48 \%$ apenas utilizando outras atividades/estratégias.

O que denomino de outras atividades/estratégias refere-se a todas as formas utilizadas pelos alunos para concluir cada disciplina do curso, tais como atividades coletivas; programas de aceleração criados pelo próprio CES; aprovações parciais em exames supletivos/ENCCEJA e aproveitamento de estudos anteriores.

É marcante a utilização que os alunos fazem de diferentes atividades/estratégias para a conclusão do curso, o que põe em cheque o modelo de percurso único, com um caminhar módulo a módulo, desconsiderando características da trajetória de alunos da EJA, e a possibilidade de atender a diversas necessidades e interesses que levam os sujeitos ao CES.

A adesão de alunos e professores aos diferentes modos de atendimento propostos parece significar compreensão sobre diferentes possibilidades da EJA nesse espaço, além de demonstrar, por parte dos 
O Que é Qualidade na Educação de Jovens e Adultos?

sujeitos, o reconhecimento da necessária interação entre aprendentes, em momentos coletivos de aprendizagem, quando há trocas em curso.

Os sujeitos - alunos e professores - demonstram perceber diferentes caminhos possíveis para situações aparentemente uniformes. No dizer de Certeau (2011, p. 46), “[...] maneiras de fazer, vitórias do fraco sobre o mais forte [...] pequenos sucessos, artes de dar golpes, astúcias de caçadores".

A fragmentação dos modos de conclusão pode ser analisada sob duas vertentes: uma que considera o comprometimento de qualidade ao resultado final; e outra que afirma ser o atendimento a jovens e adultos, implicado com suas urgências e com a necessidade de reconhecimento e legitimação de saberes construídos em outros espaços, que conformam um percurso sinuoso dos sujeitos, em busca de garantia de integridade e legitimação de saberes por meio de uma miscelânea de atividades e estratégias.

Ao se utilizarem de diferentes atividades/estratégias para otimizar a conclusão, tanto alunos quanto professores demonstraram a aceitação de modos e espaços de aprendizado diversos, assim como a existência de possibilidades inexploradas nesse modelo, e reafirmaram a capacidade humana de criar estratégias de sobrevivência diante de obstáculos que se interpunham em seus caminhos.

A diversificação desses modos de atendimento, portanto, pareceu revelar-se um caminho para a melhoria da qualidade de ensino nesse espaço, qualidade entendida como fruto da ação humana, de respeito à diversidade dos sujeitos e de percursos de formação, possibilitando aproveitamento de estudos realizados, assim como reconhecimento de saberes válidos. Esse entrelaçamento pode ter ampliado o quantitativo de certificação buscada pelos sujeitos e constituído um indicativo de que o CES pode, também, ser espaço pleno de possibilidades ainda não desenvolvidas ou subutilizadas, à medida que atendeu necessidades, interesses e expectativas dos sujeitos.

Pensando apenas sob o ponto de vista dos dados quantitativos obtidos, poderia dizer não ter encontrado indícios de melhoria da qualidade do ensino ofertado no CES Bairro B, principalmente considerando a disparidade entre o número de alunos ingressantes e os que, de fato, concluem o curso.

Mas, se considerar os diferentes modos utilizados pelos sujeitos para otimizar a conclusão, em maioria decorrentes de práticas instituintes, resultado do esforço de repensar a educação no modelo CES, posso afirmar ter ocorrido melhoria da qualidade de ensino ofertado, ainda que de maneira insuficiente e nem sempre como esperado.

\section{Para Onde Vamos?}

Nos dias atuais, quando se discute qualidade em uma escola de acesso para todos, desnaturalizam-se processos que perpetuam e le- 
gitimam modelos que não reconhecem a diversidade de sujeitos, nem variedades de modos de conhecer, de aprender e de estar no mundo. Avaliar, como resultado da ação educativa a capacidade cognitiva dos sujeitos, segue na contramão da complexa concepção de educação que pressupõe diversos espaços e modos de aprendizagem e torna necessário pôr em cheque processos educacionais em busca de um sentido diferenciado para o termo qualidade. Isso não é especificidade da EJA, mas desafio também da escola regular.

Como é possível avaliar, de maneira uniforme, sujeitos diferentes, oriundos de trajetórias descontínuas e fragmentadas? Como respeitar a diversidade de percursos sem legitimar a diversidade de modos e espaços de aprendizagem que produzem saberes? Como reinventar políticas públicas, em práticas pedagógicas cotidianas? Que maneiras de fazer utilizar em uma tentativa de diversificar modos de atendimento, adequando-os aos sujeitos que atende?

Pode-se, com Certeau (2011, p. 41), iniciar a resposta às questões, admitindo que "[...] essas maneiras de fazer constituem as mil práticas, pelas quais usuários se apropriam do espaço organizado pelas técnicas da produção sociocultural”. Mas também se deve, com o mesmo autor (Certeau, 2011, p. 43-44), entender que "[...] dispositivos semelhantes, jogando com relações de forças desiguais, não geram efeitos idênticos”, o que parece ser verdade considerando as lutas existentes no interior do próprio CES, entre professores que se inquietam com a estagnação e desgaste da escola e tentam meios de superá-la, e outros que consideram esse fato normal, devendo os alunos que não se adaptem ao modelo buscar outros caminhos.

No cotidiano do CES Bairro B surgem diariamente tensões entre práticas instituídas e instituintes, que se originam de relações humanas conflituosas e divergentes, em um espaço de convivência de pessoas únicas, com concepções diversas sobre a ação educativa.

Tendo proposto a busca de um sentido diferenciado para o termo qualidade, diante da complexidade da situação enfrentada, vi-me diante da necessidade de analisar práticas dessa escola a partir de um conceito apoiado na ideia de práxis humana, de ação humana como diferencial na busca pela qualidade de ensino, concepção que me fez compreender esse movimento de forma diversa da usual, considerando aspectos quantitativos e qualitativos, que se imbricam no interior da escola.

Uma nova qualidade, na concepção freireana, aposta no diálogo como princípio norteador da ação educativa, considerando sujeitos e relações que estabelecem como foco principal de processos de ensino e aprendizagem.

Questões referentes a relações pedagógicas, que se estabelecem nos espaços escolares, talvez tenham sido contradições do modelo original que possibilitaram e estimularam embates no interior do CES. A

Educação \& Realidade, Porto Alegre, v. 39, n. 2, p. 487-509, abr./jun. 2014. 505

Disponível em: <http://www.ufrgs.br/edu_realidade> 
desconsideração de que, ao se desenvolverem processos de aprendizagem com seres humanos, incompletos, inconclusos, se lida com a imprevisibilidade, por se tratarem de homens e mulheres não programados, que se formam e transformam na relação com o outro, com resultados imprevisíveis, fez com que os sujeitos professores envolvidos nesse processo vislumbrassem diferentes caminhos pedagógicos, que levaram a questionamentos internos e à busca de alternativas, implicados com o reconhecimento de urgências inerentes à vida adulta e à necessidade de reconhecimento de saberes construídos em outros espaços.

Os sujeitos que concluíram o curso nos anos pesquisados, assim como os que ainda cursavam, foram favorecidos por práticas pedagógicas e de atendimento instituintes, demonstrado pelos dados, diante de outros sujeitos de período anterior, quando apenas se utilizava o modelo de práticas originais do CES. Observou-se um crescimento significativo - de 1183 em 11 anos, para 6357 em 8 anos - no número de concluintes a partir da diversificação de formas de atendimento, mesmo considerados os demais fatores envolvidos, e que essas novas práticas pudessem estar imbricadas com práticas instituídas.

Considerados os processos envolvidos na efetivação do direito à educação, o movimento empreendido no CES Bairro B ao longo dos últimos anos adquire outro sentido, por representar esforço consciente de se modificarem práticas institucionalizadas, implicando visibilizar a luta permanente travada junto ao sistema de ensino, ao exigir reconhecimento e respeito a suas peculiaridades. Mesmo diante de dificuldades de conclusão de curso nesse modo de ensino, evidenciado pela imensa diferença existente entre número de matriculados e concluintes, constata-se aumento significativo após a diversificação de modos de atendimento. Em síntese, é possível afirmar que esses processos têm contribuído para a melhoria da qualidade de ensino, ao legitimar práticas humanas, que fogem à padronização.

Qualidade de ensino, entendida como respeito ao direito à educação, envolvendo condições de acesso, permanência e sucesso, respeitando especificidades da modalidade EJA e semipresencial, apoiada na práxis humana e na capacidade de intervir e modificar o mundo, implica tomada de consciência, que resulta de combinação de investimentos os mais diversos, de gestão e de ação política de indivíduos - o que é, também, um direito.

Reformar a escola por meio da transformação de suas práticas não vem sendo tarefa fácil, nem de curto prazo. Práticas mudam a partir do diálogo, utilizado como mediador de processos de reflexão e de desenvolvimento e não necessariamente representam rompimento total com o anteriormente instituído.

O CES Bairro B, como escola viva, e pelo esforço de gestores e de muitos professores, permanece tensionando o sistema complexo e amplo da rede estadual do Rio de Janeiro, salvaguardados, certamente, pela 
quase invisibilização desse tipo de escola na rede, o que tem possibilitado subversões e alternativas pouco exploradas no modelo, mediante seu compromisso com o sucesso de aprendizagem de sujeitos alunos.

Recebido em 31 de julho de 2013

Aprovado em 21 de dezembro de 2013

\section{Notas}

1 Práticas instituídas, modelo originalmente proposto; práticas instituintes, experiências de diversificação dos modos de atendimento, surgidas no cotidiano escolar.

2 Os nomes utilizados para identificar as unidades são fictícios.

3 A partir do segundo semestre de 2009, e durante todo o ano de 2010, por determinação da Coordenação de Ensino de Jovens e Adultos, foram suspensas todas as atividades diversificadas que então se desenvolviam nos CES, em preparação para uma nova Resolução, que seria publicada e alteraria o modo de funcionamento então em curso. Em 25 de fevereiro de 2011, após contínuos anúncios, a SEEDUC/RJ publicou a Resolução n. 4673 que, além de alterar a nomenclatura dos CES para Centros de Estudos de Jovens e Adultos (CEJA) e dos NACES para Núcleos Avançados dos Centros de Estudos de Jovens e Adultos (NACEJA), altera a matriz curricular e modos de atendimento. Complementa a Resolução, ainda, com determinações administrativas e revoga as resoluções anteriores que haviam, de certa maneira, possibilitado tentativas de superação do modelo de atendimento tradicional. Além disso, em 13 de dezembro de 2011, foi também publicado pela SEEDUC/RJ o Decreto n. 43.349, que transfere a gestão pedagógica do CEJA para a Secretaria de Ciência e Tecnologia (SECT), por intermédio da Fundação Cecierj, ficando compartilhada a gestão administrativa entre SEEDUC/RJ, SECT/RJ e Fundação Cecierj, situação que ainda aguarda regulamentação.

4 Em relação a essa "inconclusão legal", destaco o Parecer CNE/CEB n08/2010 - que estabelece normas para a aplicação do inciso IX, do artigo $4^{\circ}$, da Lei ${ }^{\circ}$ 9.394/96(LDBEN), que trata dos padrões mínimos de qualidade de ensino para a Educação Básica - que se encontra aguardando homologação do Ministro da Educação. O referido parecer trata do estabelecimento do chamado "custo aluno qualidade", que busca definir na legislação educacional brasileira um sentido para o termo qualidade do ensino.

\section{Referências}

ASSMANN, Hugo. Metáforas Novas para Reencantar a Educação. São Paulo: Ed. Unimep, 1998.

ASSMANN, Hugo. Reencantar a Educação. Rio de Janeiro: Vozes, 2007.

BEISIEGEL, Celso de Rui. A Qualidade do Ensino na Escola Pública. Brasília: Líber Livro Editora, 2005.

BRASIL. Constituição da República Federativa do Brasil de 1988. Disponível em: <http://www.planalto.gov.br>. Acesso em: 18 out. 2011.

BRASIL. Documento Base Nacional Preparatório à VI Confintea, 2008. Disponível em: <http://www.mec.org.br>. Acesso em: 18 set. 2012. 
BRASIL. Lei $n^{\circ}$ 9.394, de 20 de dezembro de 1996. Lei que fixa as Diretrizes e Bases da Educação Nacional. Disponível em: <http://www.planalto.gov.br>. Acesso em: 18 out. 2011.

BRASIL. Parecer CNE/CEB n ${ }^{\circ}$ 08/2010, de 05 de maio de 2010. Estabelece normas para aplicação do inciso IX do artigo 4o da Lei n. 9.394/96 (LDB), que trata dos padrões mínimos de qualidade de ensino para a Educação Básica pública. Disponível em: <http//www.portal.mec.gov.br/>. Acesso em: 18 out. 2012.

CERTEAU, Michel de. A Invenção do Cotidiano. Artes de Fazer. Rio de Janeiro: Vozes, 2011.

COIMBRA, Camila Lima; OLIVEIRA, Eliana de. Qualidade da Educação em Paulo Freire. In: COIMBRA, Camila Lima et al. (Org.). Qualidade em Educação. Série Currículo: questões atuais, v. 4. Curitiba: Editora CRV, 2011.

DEMO, Pedro. Educação e Qualidade. São Paulo: Papirus, 2009.

FREIRE, Paulo. Pedagogia da Autonomia: saberes necessários à prática educativa. São Paulo: Paz e Terra, 1997.

GADOTTI, Moacir. Educação de Adultos como Direito Humano. São Paulo: Editora e Livraria Instituto Paulo Freire, Série Cadernos de Formação 4, 2010.

LINHARES, Célia. Experiências Instituintes na Educação Pública? Alguns porquês dessa busca. Revista da Educação Pública, Cuiabá, v. 16, p. 139-160, maio/ ago. 2007.

MORAES, Maria Cândida. Por um Novo Paradigma Educacional a partir da Complexidade e da Transdisciplinaridade. In: MORAES, Maria Cândida; NAVAS, Juan Miguel Batalloso (Org.). Complexidade e Transdisciplinaridade em Educação: teoria e prática docente. Rio de Janeiro: Wak Editora, 2010. P. 7-19.

OLIVEIRA, Romualdo Portela. Qualidade com Garantia de Respeito às Diversidades e Necessidades de Aprendizagem. In: GRACIANO, Mariângela (Org.). Em Questão 4: o plano de desenvolvimento da educação. São Paulo: Ação Educativa, 2007. P. 32-34.

OLIVEIRA, Romualdo Portela; ARAUJO, Gilda Cardoso de. Qualidade do Ensino: uma nova dimensão da luta pelo direito à educação. Revista Brasileira de Educação, Rio de Janeiro, n. 28, p. 5-23, jan./abr. 2005. Disponível em: <http:// www. scielo.org.br>. Acesso em: 3 out. 2012.

PAIVA, Jane. Direito à Educação de Jovens e Adultos: concepções e sentidos. 2006. Disponível em: <http://29reuniao.anped.org.br/trabalhos/trabalho/ GT18-2553--Int.pdf>. Acesso em: 19 set. 2011.

PARO, Victor Henrique. Crítica da Estrutura da Escola. São Paulo: Cortez, 2011. PORTAL, Leda Lísia Franciosi et al. Educação Continuada: um interesse institucional na construção da inteireza dos docentes de programas de doutorado em educação de universidades do Rio Grande do Sul. Disponível em: <http://www. edipucrs.com.br>. Acesso em: 5 jul. 2011.

PORTELA, Eunice Nóbrega. A Política de Descentralização de Recursos Públicos para o Ensino Fundamental e seus Reflexos na Gestão da Qualidade do Ensino Público Municipal. 2006. Dissertação (Mestrado em Educação) - Programa de Pós Graduação da Universidade Católica de Brasília, Brasília, 2006.

RIO DE JANEIRO. Decreto n ${ }^{\circ} 43.349$, de 12 de dezembro de 2011. Transfere a gestão pedagógica dos Centros de Estudos de Jovens e Adultos - CEJA e suas modalidades da Secretaria de Estado de Educação, localizados no âmbito do Estado do Rio de Janeiro, para a Secretaria de Ciência e Tecnologia e compartilha a ges- 
tão administrativa das referidas unidades/modalidades e dá outras providências. Disponível em: <http://www.educacao.rj.gov.br>. Acesso em: 6 jan. 2012.

RIO DE JANEIRO. Resolução SEEDUC n 4673/2011, de 25 de fevereiro de 2011. Altera a nomenclatura dos Centros de Estudos Supletivos - CES, dos Núcleos Avançados dos Centros de Estudos Supletivos - NACES, estabelece critérios de classificação, para fins de fixação de quantitativos de pessoal e dá outras providências. Disponível em: <http://www.imprensaoficial.rj.gov.br>. Acesso em: 26 fev. 2011.

SANTOS, Edicleia Aparecida Alves dos; OLIVEIRA, Rita de Cássia da Silva. Caminhos e Descaminhos da Educação de Jovens e Adultos no Brasil. Disponível em: <http://www.periodicoscapes.gov.br>. Acesso em: 14 ago. 2004.

SOUZA, Graça Helena Silva de. Centros de Estudos Supletivos - CES/RJ: tensões entre o instituído e o instituinte em uma escola semipresencial para jovens e adultos. Disponível em: <http://www.anped.org.br>. Acesso em: 14 ago. 2004.

Luciana Bandeira Barcelos é doutoranda no Programa de Pós-Graduação em Educação (ProPEd), da Universidade do Estado do Rio de Janeiro, na linha de pesquisa Educação Inclusiva e Processos Educacionais. Integrante do Grupo de Pesquisa Aprendizados ao Longo da Vida: sujeitos, políticas e processos educativos. Professora da educação básica da rede pública municipal e estadual do Rio de Janeiro.

E-mail: lubbarcelosrj@yahoo.com.br 